\title{
PRODUÇÃO DE GRAFENO PELO MÉTODO DE ESFOLIACCÃO QUÍMICA E SUAS POTENCIAIS APLICAÇÕES
}

\author{
A.C. Januario'1, B.R. Remédio² e R. A. Sousa ${ }^{3}$ \\ 1,2,3 Centro Universitário das Faculdades Associadas de Ensino - Fae, Departamento de \\ Engenharia Química; Largo Engenheiro Paulo de Almeida Sandeville, 15 CEP: 13.870- \\ 377 São João da Boa Vista - SP - Brasil. \\ e-mail: ${ }^{3}$ rogerio@fae.br
}

RESUMO - As Nanolâminas de Grafeno são compostos de carbono constituídos por uma monocamada de espessura atômica extraída do grafite. Este trabalho propõe a obtenção, estudo das propriedades e aplicações de Nanolâminas de Grafeno (NG). Na produção de NG propôs-se o método de esfoliação química com modificações, diminuindo o tempo de obtenção das NG e redução no consumo de água. Tal método consiste nas etapas de intercalação das camadas de grafite, da expansão das camadas e da quebra da interação que há entre elas. As NG foram depositadas em peças de cobre, para testes de ataque com ácido sulfúrico $6,0 \mathrm{~mol} \mathrm{~L}^{-1}$. Os cubos com revestimento de NG não apresentaram modificações significativas na superfície após o ataque ácido. Além do ataque ácido, a superfície dos cubos de cobre receberam um tratamento com $\mathrm{FeCl}_{3} / \mathrm{HCl}$ para revelar a estrutura macroscópica da superfície, a qual apontou para deposição uniforme das NG com estrutura dos aglomerados bem definidas. 


\section{INTRODUÇÃO}

A relevância desse trabalho se dá pela curiosidade científica que Grafeno e suas aplicações despertaram atualmente no mundo da ciência. As nanolâminas de Grafenos são consideradas o material mais fino, no que diz respeito à sua estrutura, as quais apresentam dimensões atômicas. Além das suas dimensões específicas, as NG são mais duras e resistentes que o diamante, são superflexíveis, são transparentes, são impermeáveis e com condutividade elétrica semelhante ao do cobre, se apresentam como o melhor material condutor térmico. (CORREA 2010)

O primeiro a propor a existência do Grafeno foi o pelo físico Philip Russel Wallace, em 1947. Os químicos Ulrich Hofmann e Hanns-Peter Boehm, em 1962, nos seus trabalhos estudos com compostos a base de grafite, batizaram o material através da junção das palavras grafite e o sufixo "eno" resultando em Grafeno. Em 2004 o Grafeno despertou o interesse geral com a publicação que rendeu o prêmio Nobel de física aos dois cientistas, "André Geim" e "Konstantin Novoselov", pesquisadores do centro de nanotecnologia da Universidade de Manchester no Reino Unido, que consistia em uma fita adesiva e um grafite de lápis comum. (CORREA, 2010)

A principal característica química do Grafeno se dá pela configuração sp2 que é também unidade fundamental na formação das estruturas do grafite, dos nanotubos de carbono e dos fulerenos. (ZICA, 2013)

\section{GRAFENO}

O Grafeno é um material bidimensional (2D) com espessura monoatômica, formado por átomos de carbono com hibridização $\mathrm{sp} 2$, em que cada átomo de carbono está ligado a outros três átomos de carbono em uma estrutura hexagonal (NASCIMENTO). Os átomos de carbono possuem a capacidade de se combinarem de diversas maneiras entre si e com outros átomos para formar vários tipos de moléculas. Esta característica é devido à capacidade de formar orbitais híbridos. A hibridização é um processo pelo qual os orbitais subatômicos se combinam para a formação de novos orbitais de menor energia total. Como o átomo de carbono possui seis elétrons, no seu estado natural, eles ocupam os níveis de energia 1s2, $2 \mathrm{~s} 2$ e $2 \mathrm{p} 2$. Os três principais tipos de hibridização do carbono (sp, sp2 e sp3) dão origem a diferentes materiais (ZICA 2013).

\section{GRAFITE INTERCALADO (GI)}

O Grafite Intercalado (GI) é um composto de grafite que possui átomos agregados aos espaços entre as camadas da sua estrutura. $\mathrm{O}$ espaço contido entre as lâminas no grafite é de ordem nanométrica, possui interações fracas entre si (dipolo induzido), entretanto, ligações interatômicas são resistentes (ligações covalentes). $\mathrm{O}$ número de camadas únicas de Grafeno presentes em cada intercalação é chamado de estágio. Desta forma o número de estágios corresponde ao número de camadas de Grafeno presentes entre as camadas intercaladas. Portanto, quanto menor o número de estágios, consequentemente menor o número de monocamadas entre os agentes intercalantes, resultando em uma melhor esfoliação para a extração do Grafeno. (FIM, 2012)

O GI pode ser obtido por tratamento químico ou eletroquímico, pela adição dos ácidos concentrados. Acrescido de intensa agitação, promove-se além da purificação, a oxidação do grafite, que provoca o espaçamento nas nanolâminas (equação 1). (SILVA, C. R. E SCAPIN 2013). 


$$
n(\text { grafite })+n \mathrm{H}_{2} \mathrm{SO}_{4}+\frac{n}{2}[\mathrm{O}]+\mathrm{nHNO}_{3} \rightarrow n\left[\text { grafite }-\mathrm{H}_{2} \mathrm{SO}_{4}-\mathrm{HNO}_{3}\right]+\frac{n}{2} \mathrm{H}_{2} \mathrm{O} \quad \text { Eq. } 1
$$

\section{GRAFITE ESPANDIDO (GE)}

O grafite expandido é o produto de um tratamento térmico drástico do GI. Enquanto o GI apresenta quantidade significativas de ácido forte em suas lacunas, o qual é submetido a um choque térmico de $1000{ }^{\circ} \mathrm{C}$ por um intervalo de tempo de 30 segundos, para volatilizar os agentes intercalantes criando a expansão entre as camadas fragilizando as ligações entre os planos. (FIM, 2012)

\section{NANOLÂMINAS DE GRAFENO (NG)}

Para a obtenção das NG o GE agora com as interações interplanares enfraquecidas é submetido ao processo de banho ultrassônico para a quebra definitiva destas interações. As ligações $\pi$ quebradas agora interagem entre si formando juntamente com a ligação $\sigma$ uma dupla ligação entre carbonos vizinhos dispostos planarmente, formando uma estrutura de espessura monoatômica. (FIM, 2012).

\section{GRAFENO RESISTENTE À CORROSÃO}

Esta propriedade é presente desde a Grafita, mineral de grafite de origem (Conceitos Gerais Sobre Grafite, RELATÓRIO TECNICO 41 - Perfil da Grafita), e apresentou em menor quantidade camadas de Grafeno empilhadas formando o grafite. Testes de corrosão foram efetuados em estruturas metálicas revestidas com o Grafeno e apresentam resultados significativos com relação a proteção. Em alguns casos os resultados comprovam que o Grafeno aumenta em até 100 vezes o potencial de isolamento contra à corrosão metálica, em eletrólitos potencialmente corrosivos (MEDELIENĖ, STANKEVIČ ,GRIGUCEVIČIENĖ).

\section{OBJETIVO}

Este trabalho propõe uma metodologia para a obtenção NG utilizando esfoliação química. Além da metodologia também são propostas caracterização e aplicação das NG.

\section{MATERIAIS E METODOS}

Para a realização do trbalho utilizou-se ácido sulfúrico PA Synth, Brasil, ácido nítrico PA Synth, Brasil, clorofórmio PA Synth, Brasil, éter etílico PA Synth, Brasil e acetato de etila da marca PA Synth, Brasil O grafite usado foi de uso comercial. Foram utilizados uma balança analítica Fa 2104 Bioprecisa, um Banho ultrassônico de 1,5 litros, UNIQUE.

\section{OBTENÇÃO DAS NANOLÂMINAS DE GRAFENO}

As NG foram obtidas o método proposto por SILVA, e SCAPIN 2013; tal metodologia foi adaptada a partir do proposto por CHEN, 2013.

Inicialmente tomou-se $20,0 \mathrm{~g}$ de grafite em um elenmeyer de $500 \mathrm{~mL}$ contendo $240 \mathrm{~mL}$ de ácido sulfúrico e $60 \mathrm{~mL}$ de ácido nítrico concentrados, colocou-se a solução em agitação mecânica por 24 horas. Após este tempo deixou-se a mistura em repouso por mais 24 horas.

Nesta primeira etapa, obteve-se a GI, decantada no fundo elenmeyer, em seguida retirou-se cuidadosamente o sobrenadante, com o auxilio de uma bomba peristáltica. 
Lavaou-se o precipitado com uma solução de hidróxido de sódio $10^{-4} \mathrm{~mol} \mathrm{~L}^{-1}$, preparada anteriormente, a fim de elevar o $\mathrm{pH}$ para valores próximos à 7,0, filtrou-se a vácuo esta suspensão.

Promoveu-se a lavagem da GI que ficou contida no papel de filtro com a solução de hidróxido de sódio $10^{-4} \mathrm{~mol} \mathrm{~L}^{-1}$ e mediu-se o $\mathrm{pH}$, repetiu-se este procedimento até o $\mathrm{pH}$ atingir o valor na ordem de 7,0, em seguida lavou-se as GI com água destilada apara eliminar quaisquer traços de $\mathrm{NaOH}$ retidos na GI.

Com a ajuda de uma espátula transferiu-se a GI do papel de filtro para um cadinho de porcelana.

Realizou-se a secagem do material em um dessecador com vácuo durante 200 minutos em uma estufa a $80{ }^{\circ} \mathrm{C}$, após este tempo retirou-se o dessecador, que ficou em repouso até que atingisse a temperatura ambiente.

Levou-se o cadinho de porcelana contendo o material para a mufla a $1000{ }^{\circ} \mathrm{C}$ por um período de 30 segundos. Nesta etapa foi obtida a GE.

Transferiu-se a GE para um elenmeyer contendo uma solução de etanol 70,0 \%, colocou-se a mistura em um banho de ultrassom por 10 horas, no final, obteve-se as nanolâminas de Grafeno.

Repetiu-se o mesmo processo anterior de filtragem a vácuo (sem a hidróxido de sódio $10^{-4} \mathrm{~mol} \mathrm{~L}^{-1}$ ) e secagem (estufa e mufla) a fim de conseguir-se as NG.

\section{REVESTIMENTO DOS CUBOS DE COBRE}

Após a produção das NG usando o método de esfoliação química, cubos de cobre metálico de aproximadamente $1,5 \mathrm{~cm}$ de aresta, com as superfícies polidas, foram revestidos pelas NG.

Para a deposição foram adicionados $0,5000 \mathrm{~g}$ de $\mathrm{NG}$ em $40,0 \mathrm{~mL}$ de três solventes orgânicos distintos; éter etílico, clorofórmio, acetato de etila. Os cubos de cobre foram mergulhados nas três suspensões NG/solvente orgânico, as quais foram deixadas em repouso até a evaporação total dos solventes orgânicos. Desta forma uma fina camada de NG fico aderida à superfície dos cubos de cobre.

Posteriormente cubos revestidos ou não foram levados ao teste de corrosão, os quais receberam ataque direto de $\mathrm{H}_{2} \mathrm{SO}_{4} 6,0 \mathrm{~mol} \mathrm{~L} \mathrm{~L}^{-1}$, durante 30 minutos. Após o ataque ácido os cubos foram lavados em água destilada, secos e analisados por microscopia ótica.

Em cubos revestidos com NG aplicou-se a solução reveladora, $\mathrm{FeCl}_{3} / \mathrm{HCl}(5,0 \mathrm{~g}$ cloreto de ferro III, 30,0 ml ácido clorídrico concentrado e 100,0 ml de água destilada), esta solução é reativo para micrografia de superfícies de grãos em liga de cobre, contrastes especialmente acentuados em cristais $\alpha$ (ROHDE - 2010).

\section{RESULTADOS E DISCUSSÃO MUDANÇAS NA METODOLOGIA}

O método utilizado como base para o trabalho descreve agitação e decantação da suspensão de grafite com os ácidos sulfúrico e nítrico, drenagem dos ácidos após decantação do material em suspensão, com intervalo de 24 horas. Após a retirada dos ácidos lavava-se o decantando com água destilada e novamente esperava-se 24 horas para a sedimentação completa. Em seguida filtrava-se e lavava-se o filtrado com água destilada até obtenção de pH na ordem de 7,0 da água residual. Estas etapas do método resultavam em pelo menos 48 horas para obtenção do GI, além de desperdício de aproximadamente 10 litros de água destilada.

Portanto, propôs-se que após a drenagem dos ácidos lavar-ia-se o sedimentado com solução de hidróxido de sódio $10^{-4} \mathrm{~mol} \mathrm{~L}^{-1}$ até atingir o $\mathrm{pH}$ na ordem de 7,0 , desta 
forma o tempo foi para obtenção das GI foi reduzido em 48 horas. Além da redução do tempo na filtragem forram necessários em torno de 1,0 L de água destilada para a lavagem do filtrado.

\section{DEPOSIÇÃO COM DIFERENTES SOLVENTES}

Após a deposição das NG e o ataque ácido foram obtidas micrografias óticas, as quais apontaram para uma melhor eficiência da deposição usando-se como solvente o éter etílico, seguido pelo acetado de etila e clorofórmio. A Figura 2 apresenta as micrografias comparativas dos três solventes.

Fica evidente na Figura 2 que há formação de aglomerados de NG utilizando-se o éter etílico. Entretanto, o clorofórmio e o acetato de etila apresentam aglomerados mais discretos na superfície metálica. Este fenômeno pode ser atribuído ao menor ponte de ebulição do éter etílico $\left(34,6^{\circ} \mathrm{C}\right)$, pois com a súbita evaporação do solvente gera a deposição de aglomerados de NG mais densos.

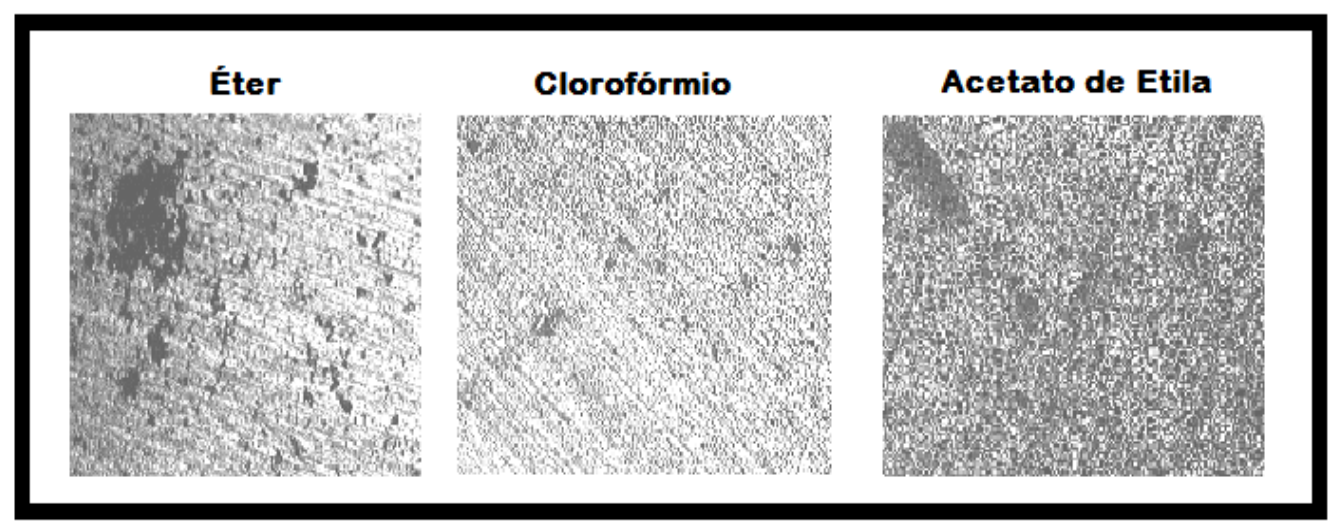

Figura 2 - Micrografias Ótica (x100) das superfícies dos cubos de cobre recobertas com NG para os três solventes orgânicos utilizados.

\section{PROTEÇÃO À CORROSÃO METÁLICA}

Os cubos testados ao ataque ácido foram monitorados durante 15 dias. Neste período observou-se que o cubo sem revestimento inicialmente tornou-se opaco e com o andar do tempo observou-se também a formação de CuSO4, evidenciado pela formação de um sólido azulado. A perda do brilho metálico pode ser atribuído à formação de poros provenientes da reação entre o cobre e o ácido sulfúrico (Figura 3). No entanto, a peça recoberta com a NG, após o ataque ácido, não apresentou mudanças significativas na superfície como pode ser observado na Figura 3.

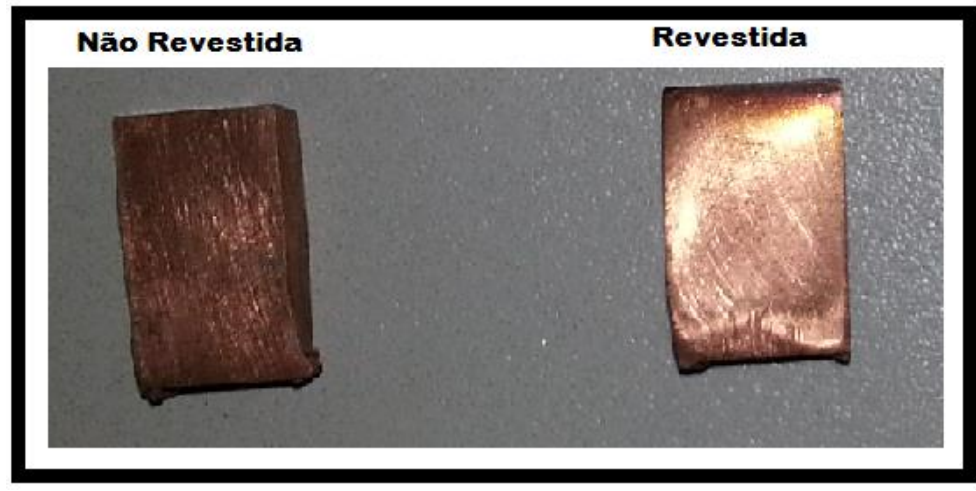

Figura 3 - Comparação entre os cubos de cobre revestidos e a não revestidos com as NG, após ataque ácido. 
As micrografias realizadas após o tratamento da superfície dos cubos com $\mathrm{FeCl}_{3} / \mathrm{HCl}$, apresentaram a formação de agrupamentos de $\mathrm{NG}$ revelando a formação de estruturas geometricamente definidas, além das estruturas ficou claro distribuição uniforme das NG (Figura 4).

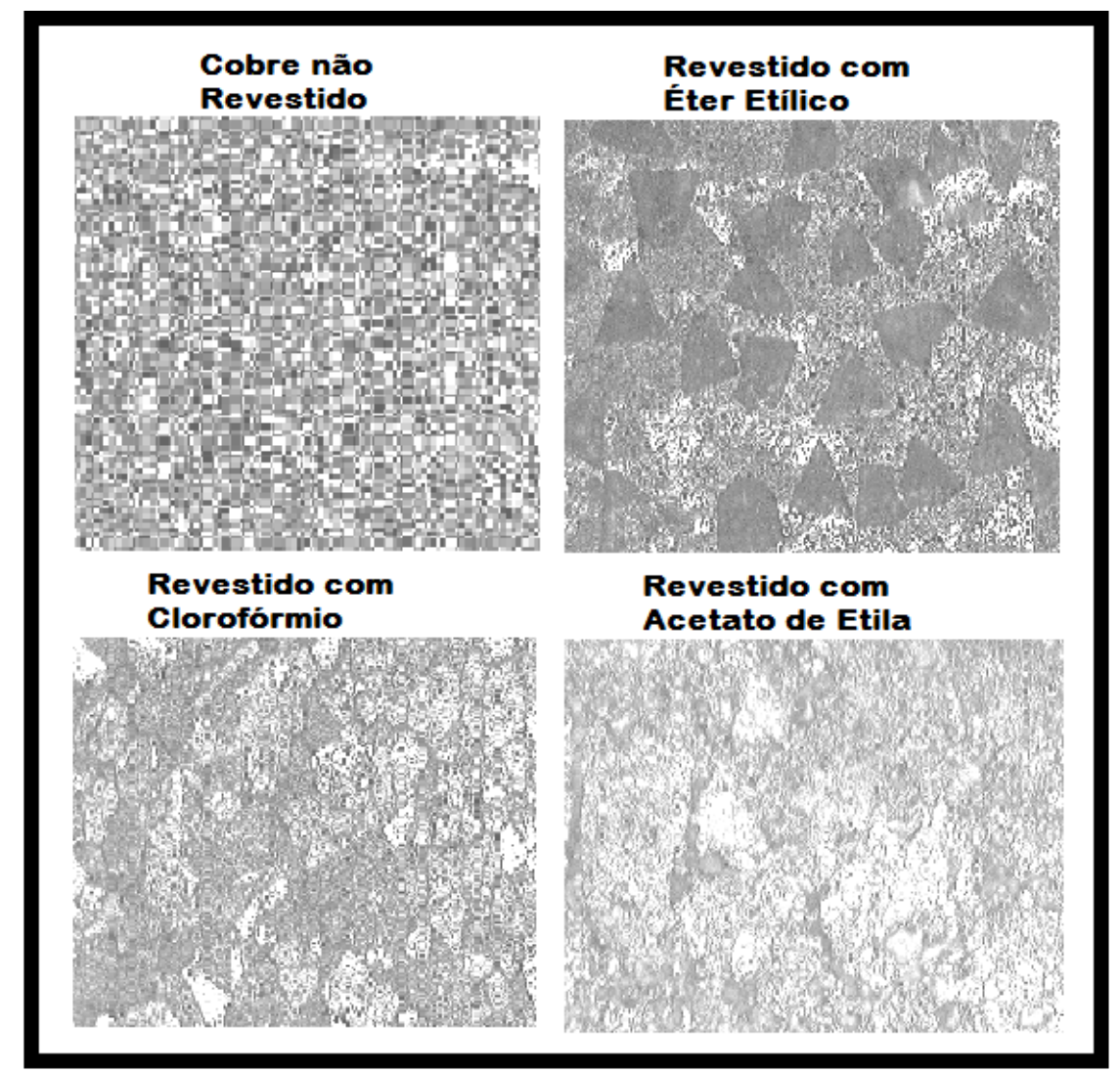

Figura 4 - Micrografias óticas obtidas para os cubos com e sem revestimento após o tratamento superficial com $\mathrm{FeCl}_{3} / \mathrm{HCl}$.

\section{Resistência Elétrica}

Foram comparadas a resistência ôhmica com o auxilio de um multímetro de bancada, entre cubos revestidos e sem revestimento de NG. Em ambos os casos a resistência foi na ordem de $0 \Omega$. Portanto, o recobrimento com NG não causou mudança significativa na condutividade do cobre.

\section{CONCLUSÕES}

Ficou evidente que as mudanças na metodologia de obtenção de NG não afetaram a produção das $\mathrm{NG}$, apenas proporcionaram economia de tempo e água destilada.

O recobrimento dos cubos de cobre com NG mostrou-se bastante eficiente na proteção superficial do ataque ácido, evidenciado pelas micrografias apresentadas anteriormente, além do tratamento superficial com $\mathrm{FeCl}_{3} / \mathrm{HCl}$ que apontou a formação de estruturas bem definidas e uniformemente distribuídas na superfície metálica gerando uma camada apassivadora minimizando os equilíbrios químicos provenientes da troca iônica metal/eletrólito na dupla camada.

Finalmente, o recobrimento não afetou a condutividade elétrica do cobre, tal como era esperado, pois as NG apresentam valores de condutividade elétrica e resistência ôhmica semelhantes ao cobre. 


\section{REFERÊNCIAS}

CORREA D. R. N. A síntese do Grafeno: O premeio Nobel de Física de 2010 - 2010

CHEN, G. Carbon. [S.1]: [s.n.]Vol 41, 2003. p. 579-625.

FIM, A C. Síntese e Propriedades de Nanocompósitos de Polietileno/Nanolâminas de Grafeno Obtidos Através de Polimerização In Situ. 2012. 90p. Tese (Doutorado) Faculdade de Ciência dos Materiais, Universidade Federal do Rio Grande do Sul, Porto Alegre, 2012.

FRAZIER, Rachel M., DALY, Daniel T., SWATLOSKI, Richard P., HATHCOCK, Kevin W. Recent Progress in Graphene-Related Nanotechnologies. Recent Patents on Nanotechnology, 3, p.164-176, 2009.

GEIM, A. K. e NOVOSELOV, K.S.; The rise of graphene; Nature; 2007,vol 6.

MEDELIENĖ V., STANKEVIČ V., GRIGUCEVIČIENĖ A., SELSKIENĖ A. e BIKULČIUS G. - The Study of Corrosion and Wear Resistance of Copper Composite Coatings with Inclusions of Carbon Nanomaterials in the Copper Metal Matrix)

NASCIMENTO, J. P. - Esfoliação do Grafite Natural em N-metilpirrolidona e Clorofórmio para Obtenção de Grafenos -

ROHDE, A. R. Metalografia Preparação De Amostras - Uma Abordagem Pratica 2010.

SILVA, C. R. e SCAPIN, K. Síntese do Grafeno e Produção de Nanocompósitos Poliméricos. Trabalho de conclusão de curso - Centro Universitário das Faculdades Associadas de Ensino - UNIFAE, 2013.

ZICA, A. S. Esfoliação Eletroquímica, Deposição Eletroforética e Caracterização de Nanofolhas de Óxido de Grafite. - Dissertação apresentada à Universidade Federal de Viçosa, como parte das exigências do Programa de Pós-Graduação em Física Aplicada, para obtenção do título de Magister Scientiae - 2013. 